\title{
AFTER-CARE AND PROPHYLAXIS AND THE HOSPITAL
} PHYSICIA'N.*

By Adolf Meyer, M.D., LL.D.,

DIRECTOR OF THE PATHOLOGICAL INSTITUTE OF THE NEW YORK STATE HOSPITALS, AND PROFESSOR OF CLINICAL MEDICINE (PSYCHOPATHOLOGY)

CORNELL UNIVERSITY MEDICAL SCHOOL

At the request of our President I have been induced to report briefly on a movement which has been inaugurated in New York State for the purpose of after-care of needy persons discharged from hospitals for the insane. What Dr. Wise, Dr. Stedman, Dr. Dercum, Dr. Dana, and Dr. Dewey had advocated since r893, has at last been realized and put in operation.

Largely through the efforts of Miss Louisa Lee Schuyler, the Conference of Superintendents of the State Hospitals of New York has requested the State Charities Aid Association to organize a system of after-care for the insane, and to put it into practical operation. It passed a resolution "That in the opinion of this conference it is desirable that there shall be established in this State, through private philanthropy, a system for providing temporary assistance, and friendly aid and counsel for needy persons discharged recovered, from State Hospitals for the Insane, otherwise known as "After-Care of the Insane."

This inaugurates a system of co-operation between the State Hospitals and an organization of private philanthropy and makes possible a co-operation of paid agents and of volunteers; the expenses to be paid by voluntary contribution, and with the utilization of the allowance provided by the State of an amount up to $\$ 25.00$ for patients discharged and in need of help to "defray his necessary expenses until he can reach relatives and friends or find employment to earn a subsistence."

The State sub-committee on after-care consists of six members from the State Charities Aid Association, and as organization progresses, each hospital district will receive its special after-care committee; Marhattan State Hospital has a committee consisting of five members of the State Charities Aid Association and two members from the board of managers of the hospital, and the superintendent. The Willard After-care Committee has seven

\footnotetext{
*Read at the meeting of the American Neurological Association, June
} 4 and 5 , I906. 
members from the State Charities Aid Association, three members of the board of managers, and the superintendent of the hospital. There has already been an agent appointed to work in connection with Manhattan State Hospital. The formal expenses of salary, traveling and other after-care expenses are expected to amount to about $\$ 2,500$ annually, and in addition to the allowance up to $\$ 25$ assured by the State, private contributions will be resorted to for practical assistance of individuals.

In the main the system of the English After-care Society seems to have been the chief model of the movement inaugurated, apart from the fact that more is made of a co-operation of the hospitals with the local Committee, and that really a co-operation between State and private philanthropy is assured. This special fact is very gratifying. In a paper read by me at the conference at which the State Charities Aid Association was authorized to take up the co-operative work, I made a strong appeal in favol of as close as possible co-operation between the physicians who have charge of the patients and any individuals who wish to help the patients outside. The failure of the previous efforts in such a movement in this country comes, to a large extent, from a lack of conviction on the part of hospital physicians concerning the efficiency and desirability of the ordinary type of charitable movements. And I am also convinced that unless there is a hearty co-operation between physicians and philanthropists, the movement loses its greatest opportunity and its main spring wrich would assure its life and its development into that which we really need most of all,-namely, the breaking down of the hospital walls, the extension of responsibility of the physician to the prevention of relapses, and the responsibility of carrying useful information gained in hospital practice to our intermediators among the public - the physicians, and those who have the broader sociological problems of the community at heart. This country is fortunately not a region in which pauperism is an inevitable doom of a certain portion of our population. Large cities may offer numerous samples of destitution requiring monetary aid, but as a rule our people are proud of supporting themselves; they like to make their own way, and wholly friendless individuals are extremely rare. The main need is that of guidance to a field best adapted to the qualification of the patient, and especially also guidance of their environment in the direction of adequate help 
and strengthening of the healthy instincts in the struggle against morbid tendencies.

In trying to do the work with the insane as conscientiously as possible, and in interesting our colleagues in the service, certain needs have become evident which ultimately will have to be taken up by the after-care associations.

In the first place, the desirability of encouraging and organizing in each community persons capable of spreading sound information concerning what the State can and will do for victims of mental disorders.

2nd: The encouragement and organization of individuals who will have enough interest in the cause to help the hospital physician get at the correct estimate of the conditions under which the patient was wrecked, and to which the patient shall be discharged, $i$. e., persons to be appealed to in obtaining direct information.

$3 \mathrm{~d}$ : Persons who will be willing to relieve the tension between the public and hospitals, usually based on misinformation.

4th: Persons who have a sufficiently wide acquaintance with the opportunities of a locality for drawing a recovered patient as rapidly as possible into a healthy and wholesome environment, that is, persons who have contact with movements by no means exclusively looking out for persons who have been insane. Much help is obtained from churches, from charity organizations of an independent character, from abstinent societies, and from all those who are leaders of interests in the various strata of our healthy population. The issue is to make all the possibilities accessible.

In this whole movement we physicians can do a great amount of good by helping in the co-ordination of all the individuals who might be accessible to interests,-leaders among the various strata of the healthy, flysicians, schoolmen, leaders of social movements, workers against alcololic excesses, judges, clergymen; to attract their attention to the available reports, to organize some public lectures on matters which seem to be specially in need of elucidation in a community, to distribute such lectures, and to gradually replace the nctions of half a century ago by the facts available at the present time.

The New York Psychiatrical Society aims to make a be- 
ginning in this direction, and it is hoped that other bodies will follow.

In closing I should like to emphasize an appeal for harmonious working, for a disinterested assistance to the hospital men, who after all assume the greatest responsibility about the fate of the patient, and well considered co-operation of any after-care and prophylaxis movement in each community. But first of all, I should urge the necessity of dropping the narrow-minded habit of considering the restrictions under which hospital-physicians work as inevitably those of sequestration. Let us help the hospitalphysician broaden his horizon and overcome the diffidence imposed on him by tradition and prejudice. He should be the center of work for the patient, the collector of all the information and therefore the one who will also be the central figure in the aftercare steps. Give the hospital-physician the chance and you will see that the chief obstacle in the way of after-care is overcome. Twelve years have elapsed since the committee's report. Since then much has changed, inside the hospitals and outside. Civic medicine has made much practical progress and has learned and taught some good lessons in the duties and possibilities of popular education, in social and personal hygiene and prevention. Let us use what the tuberculosis struggle has taught us, and above all, let us encourage those who more than ever try to rise from the oppressed and artificially sequestrated positions of hospitalphysicians. Let us help those who have the patient under their care for months or years ; let us widen their sphere of interest and responsibility beyond the temporary mending; let us create links between them and the public and the places to which the patients return. Interest and responsibility grow with opportunity. If physicians in hospitals know that physicians and others outside will profit from a knowledge of facts in a patient for the purpose of directing local after-care work, a natural diffusion of information will begin, much to the advantage of all concerned. With this additional appeal $I$ heartily endorse the recommendations made by Dr. Stedman in his admirable presidential address. 